AGH DRILLING, OIL, GAS • Vol. $31 \cdot$ No. $1 \cdot 2014$

http://dx.doi.org/10.7494/drill.2014.31.1.59

\author{
Krystian Liszka*, Mariusz Laciak*, Andrii Oliinyk*
}

\title{
ANALYSIS OF NEW GENERATION ODORANTS APPLICABILITY IN THE POLISH NATURAL GAS DISTRIBUTION NETWORK
}

\section{INTRODUCTION}

Odorization is a process of top importance for the safety of natural gas distribution and use. Small concentrations of odorants of distinct and characteristic smell are admixed to the naturally odor-free natural gas. It is extremely important to trace the leaks in gas appliences, installations and systems at considerably low concentrations of gas in air. According to the Polish regulations the operators of gas distribution networks are obliged to provide the customers with fuel which is odored to such a level that in the case of a gas leak the alarm concentration in the air corresponds to $20 \%$ of Lower Explosive Limit (LEL). For natural gas representing E-group the 20\% LEL corresponds to ca. 1 vol. $\%$ of gas in air. The correct level of network gas odorization can be maintained thanks to the odorization technology which has been developed over the last tens of years. The present technology of gas odorization used in Europe can be defined as mature. The applied tools guarantee the proper level of gas odorization. The odorant concentration in gas is constantly monitored and the odorants are high quality products delivered by renown producers. By the end of the 20th century the odorization of natural gas was based on substances containing considerable quantities of sulphur. In late 1990s attempts were made to find substances which could be used as odorants and yet which would have a more neutral environmental effect. As a result of years of experiments and tests a new sulphur-free odorant was worked out. It was first applied as Gasodor S-Free in 2001, and thanks to its good properties found a growing interest on the market.

* AGH University of Science and Technology, Krakow, Poland 


\section{ODORANTS USED SO FAR}

Prior to the natural gas era the fuels did not have to undergo odorization. Gaseous fuels produced in local gas or industrial plants, and distributed through the municipal networks contained compounds with very strong and distinct smell. Municipal gas produced in coalfired gas plants contained aromatic sulphur compounds.

Historically the first conscious odorization process was performed by a German scientist of Italian descent named von Quaglio in 1880. While looking for leakages in installation he added ethyl mercaptan to the gas [11]. The network gas odorization started in U.S.A. in late 1930s. On March 18, 1937, as a consequence of an odor-free gas explosion, a school building was destroyed in New London, Texas killing and burying over 300 people [3]. After this tragic accident the authorities decided to make natural gas odorization obligatory.

In Poland, after World War II, when the gasification based on high-methane gas extraction in the Carpathian Foredeep was developing, there appeared a safety issue and the related need to intensify the smell of the produced gas. Initially the gas was odored with sulphur-free polycyclic hydrocarbons, e.g. dicyclopentadiene (DCP). However a number of exploitation problems arose. The substance had to be dosed in very high concentrations. A low vapor pressure created difficulties with maintaining the appropriate level of odorization. Undesirable and dangerous odorant re-condensing could take place in the case of pressure increase or drop of gas temperature. The DCP dosing installations had to be monitored as an uncontrollable overodorization could take place in the case of a rapid gas flow through the gas station. The successively introduced sulphur-based odorants had most of DCP disadvantages also some very important advantages, i.e. vapor pressure which was several times higher than that of DCP (thanks to which the condensation could be stopped), and very distinct and easily recognizable smell.

The law about the scope of gaseous fuel odorization specifies requirements set before odorants. Generally, odorants added to a gas should not cause any chemical or physical changes in the fuel (except for the smell) and yet be easily detectible through our noses even in very low concentrations.

An optimum odorization agent which can be added to natural gas distributed through a public network should meet a number of conditions. Among the most important ones are:

- characteristic, easily recognizable smell that does not naturally apear in the environment of a man,

- sufficiently high vapor pressure,

- environmentally safe combustion products,

- easy transport, storage and pumping of dosing installations,

- no negative impact on materials from which gas pipelines and odorization installations have been made,

- proper stability and resistance to oxidation,

- any negative impact of vapors and liquids on human organism within admissible and safe level,

- price which is acceptable to the network operators. 
Sulphur odorants have been used over the world since 1960s. Now they constitute $100 \%$ of odorants used in Poland for natural gas odorization. Among the most popular ones are (Table 1):

- tetrahydrothiophen (THT),

- ethyl mercaptan (EM),

- tert-butyl mercaptan (TBM).

Table 1

Selected sulphur odorants

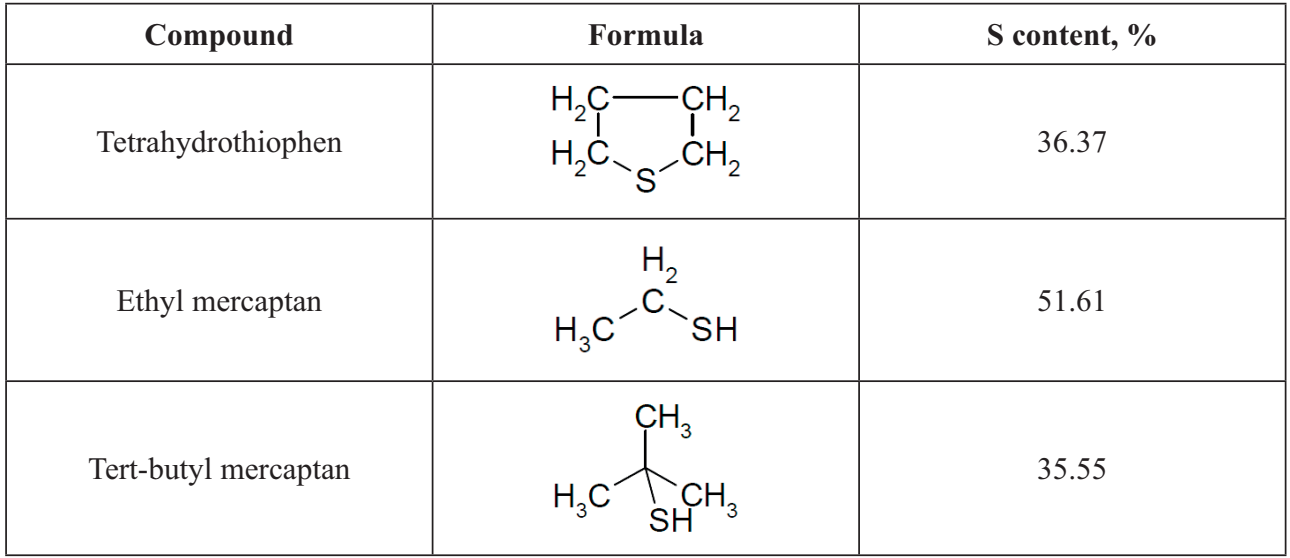

The main producers of conventional sulphur-based odorants are chemical concerns, e.g. Arkema and Chevron Phillips. Available commercial products are usually so composed mixtures as to bring about their desired physicochemical properties. TBM has a high pour point of $+1^{\circ} \mathrm{C}$, therefore its mixtures have to be applied.

\section{SULPHUR-FREE ODORANT}

About $0.2 \%$ of anthropogenic $\mathrm{SO}_{2}$ emissions in Europe presumably come from the combustion of sulphur odorants in natural gas [2]. The simulation of ecological effects of sulphurfree odorant use for odorization the entire volume of natural gas in Germany is illustrated in fig. 1. The calculations were performed for different concentrations and various types of odorants.

On the background of proecological activities in 1995 an idea was born in Germany to substitute traditional odorants commonly used in world's gas industry with more environmentally-friendly substances. The gas concern Ruhrgas AG and a chemical company Haarmann\&Reimer (producer of odorant substances for perfumery industry, etc.) initiated works on a recipe for a sulphur-free odorant which would meet the requirements set before natural gas odorants. 


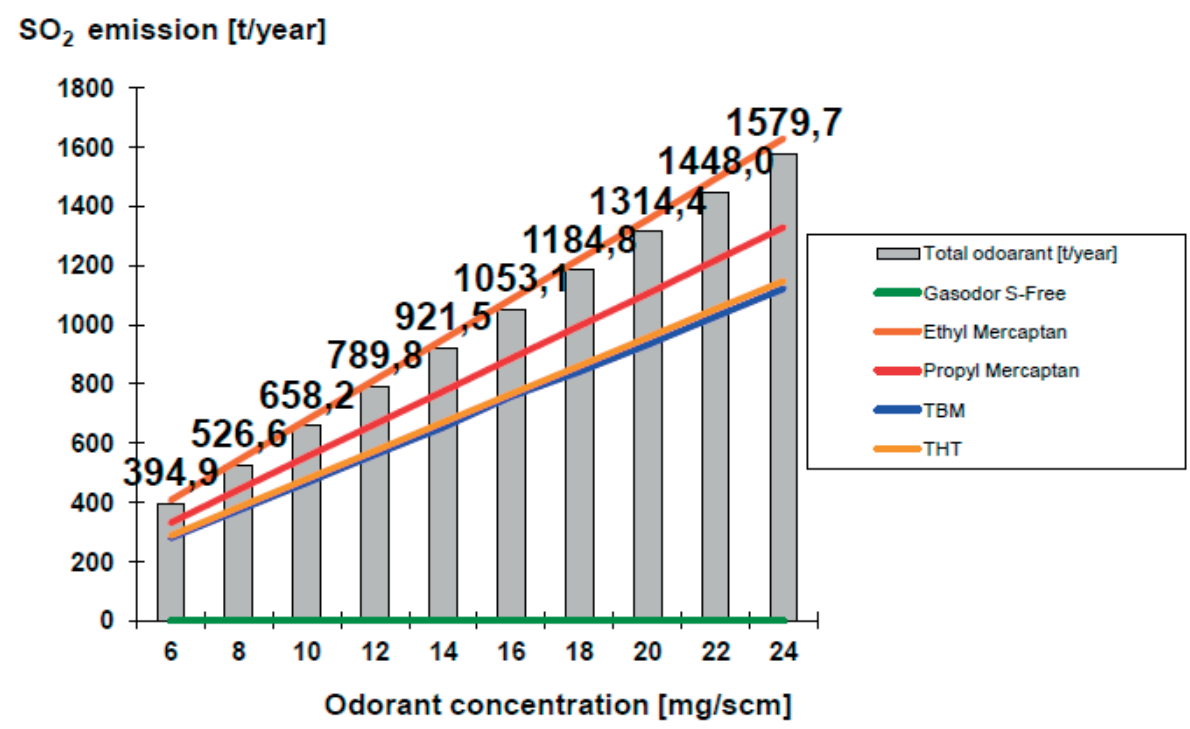

Fig. 1. Simulation of $\mathrm{SO}_{2}$ emission produced by combustion of a gas odored with various odorants, depending on their dose

Source: Symrise AG materials.

A team of scientists from the University of Karlsruhe in cooperation with Deutsches Verein des Gas und Wasserfaches (DVGW) performed a number of experiments and tests with various substances, on the basis of which a recipe for a new odorant was worked out.

As a result a mixture was elaborated. It consisted of known substances which had been already used for the production of plastics, fibres, medicines, glues and paints.

The new product was patented in 1998 as an odorant for natural gas distribution networks.

In 1999 comparative tests were made with other odorants. They confirmed that the new odorant met all requirements set before odorants and can be used for odorization gaseous fuels. The new product was given the trade name of Gasodor S-Free. Now it is produced by the chemical concern Symrise AG in Holzminden, Germany.

On March 21, 2001 the Gasodor S-Free was first introduced to the natural gas distribution network in Philippsburg. The network was about $71 \mathrm{~km}$ long and supplied gas to about 1500 customers. Since that moment the participation of the new odorant started to rapidly increase in Germany [5]. Since 2004 Gasodor S-Free has been also successfully used for odorization high-pressure central gas systems.

At present, dozen years later, the share of sulphur-free odorant on German market amounts to over 30\%. Apart from Germany, where this product is used in Hamburg and Dortmund agglomerations, there are also other countries where it is applied, e.g. Austria, France, Switzerland, Turkey, Sweden and China. Other countries are also about to implement it, e.g. Italy and Poland. 
In the atmospheric pressure and use temperature conditions Gasodor S-Free is a colorless or off-brown fluid of density $933 \mathrm{~kg} / \mathrm{m}^{3}\left(25^{\circ} \mathrm{C}\right)$. It is a mixture of ethyl acrylate and methyl-ethyl pyrazines (Table 2). The polymerization taking place during transport and storage is counteracted by adding trace amounts of a stabilizer Ionol (2,4-dimethyl-6-tert-butylphenol). Thanks to the presence of the stabilizer the odorant may be transported and stored in steel drums commonly used in the odorization technology. The tests performed by the producer proved the resistance of the product to polymerization for at least 2 years at the storage temperature up to $50^{\circ} \mathrm{C}[1]$.

Table 2

Chemical composition of Gasodor S-Free

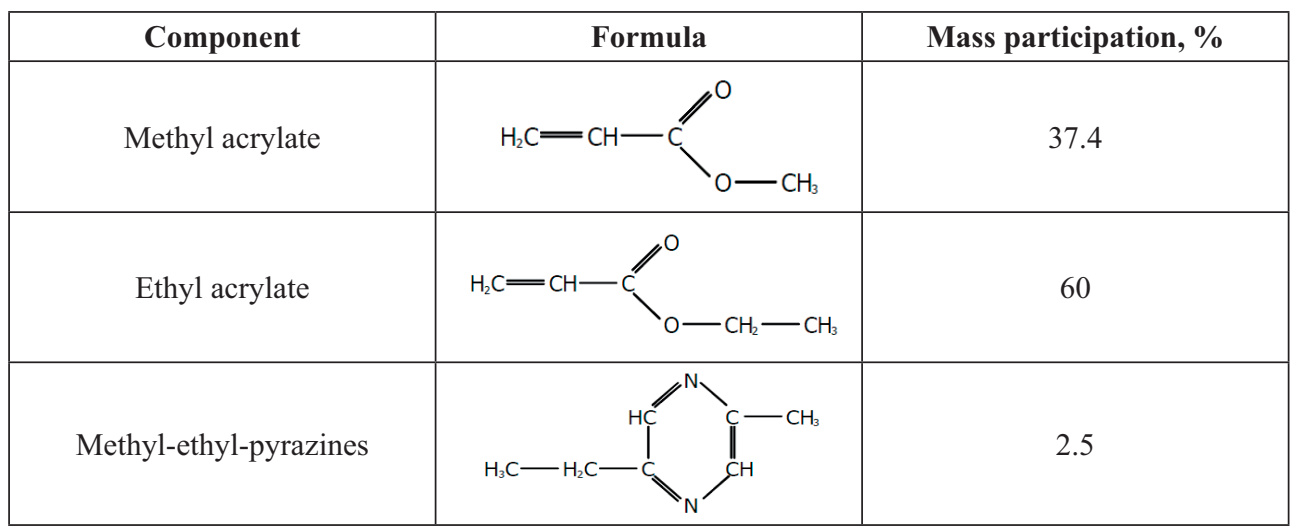

The melting temperature of Gasodor S-Free ranges between -80 and $-110^{\circ} \mathrm{C}$, the ignition temperature equals to $395^{\circ} \mathrm{C}$. The vapor pressure at a temperature of $25^{\circ} \mathrm{C}$ equals to 82 $\mathrm{hPa}$. The residue after evaporation constitutes less than $0.07 \%$. This is a flammable and explosive product. The explosive limit for its air mixture oscillates between 1.6 and $23 \%$. The physicochemical properties of the product meet the requirements set before odorants used in installations with volumetric control of dosing.

The minimum alarm concentration $(\mathrm{K})$ of Gasodor S-Free in an air mixture of gaseous fuel is $0.07 \mathrm{mg} / \mathrm{m}^{3}$, i.e. slightly lower than for tetrahydrothiophen. The relatively low value of minimum alarm concentration $\mathrm{K}$ causes that the new odorant can be efficiently dosed from about $9 \mathrm{mg} / \mathrm{m}_{\mathrm{n}}^{3}$.

The character of smell was analysed on a large-scale on a population of 113 persons at the University of Karlsruhe in 1999. The smell of the new odorant resembled that of other odorants, but still was slightly different. The specific character of the smell is its additional advantage. During the experiments the scientists used mixtures containing THT, TBM, Gasodor S-Free as well as the smell of a fish, baked meat, jasmine and pure air. The test group clearly confirmed that the smell of the odorants was aggressive, irritating and 'chemical'. The impact level of the sulphur-free odorant was observed to be strongest (Fig. 2). 


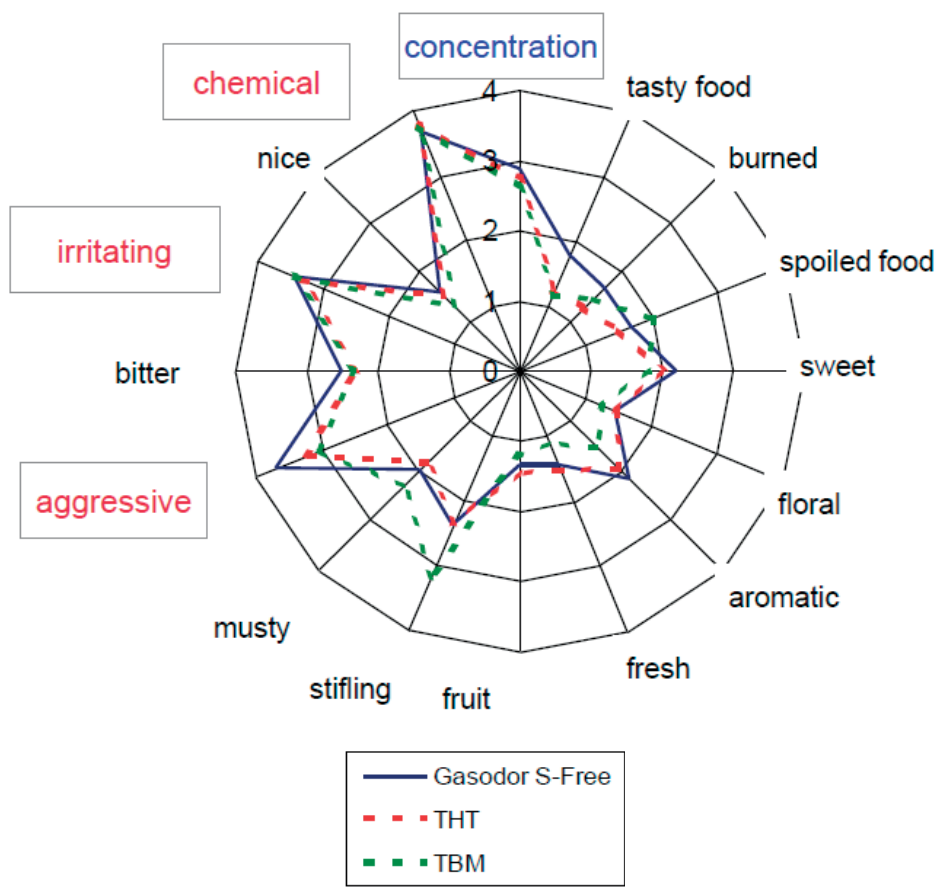

Fig. 2. Results of analyses of type and intensity of odorants Source: Symrise AG materials.

The natural reaction of the test group to Gasodor S-free odorant was to immediately leave the test room. Unlike THT and TBM Gasodor S-free has a unique smell which cannot be found in the natural environment of a man, which gives an additional advantage to this product. The results indicate that the smell of Gasodor S-free has the features of an ideal odorant [10].

The acrylate compositions were also used in the new odorants, therefore it was analyzed for the hygienic and sanitary aspects. The tests performed on humans and animals revealed individual alergic reactons to high concentrations of methyl acrylate and ethyl acrylate applied onto the bare skin. No negative impact was observed on the respiratory system, though care has to be taken and protective clothes used when working with the liquid odorant. The acrylate vapor concentration in odorized gas is so low that no allergic reaction in humans is possible [7].

The carcinogenicity and mutagenic influence of ethyl acrylate on human organisms did not prove any correlation between exposure to acrylates and frequency of incidence [6].

The specific character of smell and its proper influence on the clients of gas companies has been proved by a comparative analysis of gas leakage calls in areas where various odorants were used. The analysis of about 8000 gas leakage calls before and after the odorant was changed revealed that the index of confirmed leakages was $78 \%$ for Gasodor S-Free, and $43 \%$ 
for THT [4]. These data show to the possibility of obtaining additional savings on the number gas emergency interventions. In the macro-scale, the smaller is the number of calls, the lower is the number of employees, the lower are the costs and the better is the competitiveness of the company.

\section{INFRASTRUCTURE FOR NATURAL GAS ODORIZATION IN POLAND}

In Poland over 1500 odorization plants are in use now, and predominantly they are part of gas systems. The odorization installations are owned by operators of gas distribution systems and operators of gas transport systems. In view of the legal requirements only the operators of gas distribution systems are responsible for the correct odorization of fuel therefore only they will be the users of odorization installations. At present the odorization is realized by dosing THT to the gas $\left(20-30 \mathrm{mg} / \mathrm{m}_{\mathrm{n}}^{3}\right.$.)

The odorization process may be realized with the use of local odorization stations, localized at gas outlets from the transmission system, or centrally. The central odorization lies in dosing an odorant to the natural gas transported through a pipeline at a high pressure to a given distribution network. There is no necessity of placing dosing installations at each gas outlet, which is obviously very advantageous. The central odorization has also a few disadvantages. The biggest problem is related with the fact that the entire stream of gas has to be odorized, regardless its destination. It should be noted that gas for industrial purposes, after meeting certain conditions, may remain unodorized. Some gas customers run technological processes in which odorized gas could cause premature wearing away of equipment, costly catalysts in particular. Odorization in high pressure conditions with the use of sulphur compounds also causes exploitation problems resulting from the adsorption of odorants on the pipeline walls, adsorption in dust and absorption in condensates left out after the compression processes. The sulphur content in gas increases the corrosiveness potential of the sent medium. Mainly for these reasons the central odorization plants tend to be closed and more expensive, local ones opened.

In Polish gas industry gaseous fuels are principally odorized with the use of two methods:

- contact of odorant vapors with gas flowing above the surface of the liquid, known as contact odorization,

- volumetric dosing of liquid odorant to the stream of flowing gas, known as injection odorization.

The analyses of Gasodor S-Free in view of its applicability absorption odorization plants were performed at the Oil and Gas Institute in Kraków in 2011. The results of odorant evaporation confirmed that particular components of the product evaporated to a different degree, especially at higher temperatures. This behavior is congruent with the course of plots representing pressures of constituent vapors. The changes in the concentration of the components had an influence on the typical smell of the odorized gas. They did not have any influence on the intensity of smell. The residue left after the evaporation had an oily form [8]. 


\section{PERSPECTIVES OF USING GASODOR S-FREE IN POLAND- POSSIBLE PROBLEMS}

Bearing in mind formal aspects, there are no formal obstacles for new odorant to be used in Poland. Gasodor S-Free received all certificates and can be safely implemented. It was also given a positive opinion of the Oil and Gas Institute in Kraków, certifying that all required criteria set in standard PN-EN ISO 13734: Natural gas - Organic sulphur compounds as odorants - Requirements and research methods have been met. At the same time the Gas Economic Chamber worked out a Technical Standard defining guidelines for sulphurfree odorants. However there are still many areas requiring detailed analysis and preparatory works to make the replacement of the odorant safe and efficient.

\subsection{Uniqueness of smell}

Gasodor S-Free has a very unique, characteristic, unpleasant and irritating smell which is its great advantage. This property is also very inconvenient as this smell slightly differs from the well known smell of sulphur-based substances, especially THT. After tens of years the customers got accustomed to conventional odorants therefore the replacement of the traditional one has to be preceded with well planned actions. No matter whether a sulphur-free odorant is implemented in the new network or the odorant will be replaced, prior to this operation the clients have to be informed about the change of the smell. In Germany smell samples were distributed, which turned out to be very effective. During gasification of new areas an assumption may be made that customers do not know the smell of sulphur-based odorants. Conventional odorants are added in great quantities to liquid gas, which is commonly used for heating purposes or in mechanical vehicles. Their clients already got accustomed to the smell of gas. A broad informative action is absolutely necessary and should be performed with the use of local information channels.

\subsection{Odorization control}

The level of natural gas odorization may be defined directly with the use of olfactometric techniques. Oflactometry provides advanced measurement methods directly informing whether the gas-and-air mixture of a given concentration has an alarm smell or not. The odorized mixture is checked out organoleptically and then the intensity of odorization is assessed. The methodics of direct evaluation of smell intensity requires specialist equipment, trained personnel and much time for the tests. In view of regulations, according to which the gas in air should be odorized to a proper level, and olfactometry should be the main way of checking out the correctness of odorization. However, due to the complications mainly related to the imperfect operation of the sense of smelling, subjectivism of evaluation, organoleptic method is not commonly used in Poland. Maybe in the future, after commercialization of ,electronic noses” the situation will be changed and direct measurement of odor intensity becomes reliable, cheap and objective.

An indirect method of determining the smell level lies in measuring the concentration of an odorant dissolved in natural gas. There are a number of detectors for determining concentrations of sulphur odorants in fuel. The simplest ones are equipped with electrochemical 
factors and are used for measuring odorant concentrations with accuracy $1-2 \mathrm{mg} / \mathrm{m}_{\mathrm{n}}{ }^{3}$. The total sulphur in gas is most frequently measured and the result is recalculated for the concentration of a given odorant. More complex systems employ, e.g. gas chromatography thanks to which the concentrations of odorants, their mixtures and other gas components can be accurately determined. In Poland in majority of cases the odorant concentration is measured at specilist laboratories owned by operators of distribution networks.

When applying a sulphur-free odorant, the problem lies in determining small concentrations of acrylates in natural gas. At present there are no cheap and simple systems with which acrylate concentrations in natural gas can be accurately measured at the level of $0-20 \mathrm{mg} / \mathrm{m}_{\mathrm{n}}{ }^{3}$. The measurements are performed with the use of advanced instruments based on gas chromatography methods or IMS (Table 3).

Table 3

Systems for determining concentrations of Gasodor S-Free [4]

\begin{tabular}{|c|c|c|c|c|}
\hline \multirow[b]{2}{*}{ Type } & (Micro-)GC & IMS-Odor & $\mu$ IMS-Odor & CMS Analyzer \\
\hline & & & & \\
\hline $\begin{array}{c}\text { Measurement } \\
\text { principle }\end{array}$ & chromatography & $\begin{array}{l}\text { spectrometry mobility } \\
\text { of ions }\end{array}$ & $\begin{array}{l}\text { spectrometry } \\
\text { mobility of ions }\end{array}$ & $\begin{array}{l}\text { calorimetry } \\
+ \text { sensor }\end{array}$ \\
\hline Mobility & mobile, stationary & stationary & mobile & mobile \\
\hline $\begin{array}{c}\text { Measurement } \\
\text { range }\end{array}$ & $1.5 \mathrm{mg} / \mathrm{m}^{3}$ & $4-23 \mathrm{mg} / \mathrm{m}^{3}$ & $0-23 \mathrm{mg} / \mathrm{m}^{3}$ & $3-30 \mathrm{mg} / \mathrm{m}^{3}$ \\
\hline
\end{tabular}

The analytical systems are also available in mobile variants, but their price is too high to justify the cost of the analysis. In Germany the measurement of Gasodor S-Free concentration does not create any problem because the odorant concentration analyses are performed more rarely there. They are ordered by gas companies at independent laboratories. In this solution the measurement equipment is better used and the gas supplier does not have to invest in own laboratories.

In the Polish conditions the respective regulations impose an obligation on the operator of distribution network to measure the odorization level at least twice a month. The high frequency of measurements and the high price of equipment for measuring acrylates is a serious obstacle for the implementation of the new odorant in Poland.

\subsection{Sealing of odorization instalations}

Membranes of reduction systems and all types of filters, seals of technological devices and gas receivers can be exposed to the negative impact of other substances than 
hydrocarbons. The tests did not prove the negative influence of sulphur-free odorant vapors dosed in working concentrations on materials from which network or gas appliances are made. The analyses performed by, among others, Oil and Gas Institute in Kraków show that there is no negative effect of Gasodor S-Free vapors on reducer membranes and other materials used in gas industry for sealing [8].

The situation is slightly different when some sealing materials contact the liquid odorant. Various types of sealing materials are used in the injection odorization installations. The constitutent elements of dosing installations are usually performed from acid-resistant steel and the connections are protected with, e.g. teflon, silicon or other specialist materials.

According to the literature data [5], the destructive activity of liquid Gasodor S-Free on the materials used by some producers of odorization installations, was observed for:

- Viton (fluoroelastomer),

- silicon,

- NBR, Perbunan (nitrile rubber),

- HNBR (high-saturated nitrile rubber).

No negative impact was observed for:

- teflon (PTFE),

- Kalrez, Viton Extreme, Isolast (fluoroelastomers).

Therefore it is necessary to check out and classify all parts of the installation which could have a contact with liquid odorant. Then should follow the replacement of seals or components which were made of inappropriate materials.

\subsection{Safety of odorant replacement operation}

The odorant replacement operation in a given distribution area should be preceded by preparatory works. Attention should be paid to the considerable number of activities to be planned and realized. Among the most important ones are:

- information action in which the customers will be informed about the new smell and the term of the replacement,

- work out procedures and instructions how to handle the new product,

- train the personnel,

- certify the congruence of materials from which odorization installations are made,

- inform institutions responsible for security issues,

- provide efficient neutralizers for possible leakages,

- measure concentration and/or odorization level at the required frequency,

- monitor the odorant conversion process in representative points of the network,

- provide reserves of new odorant and its storage place.

According to the literature data, no serious problems with odorant replacement have been encountered, even in large-scale projects where tens of thousands customers were 
involved [9]. For the safety reasons, initially the odorant dose is usually increased to about $20-25 \mathrm{mg} / \mathrm{m}^{3}$. Then it is gradually decreased to the target level of about $12-14 \mathrm{mg} / \mathrm{m}^{3}$ during a few weeks. At the initial stage an increased number of leakage calls are observed. This is also connected with the effectively performed information action.

\section{CONCLUSIONS}

1. Literature data and exploitation experience prove that Gasodor S-free meets the requirements set before odorants and has been successfully used in distribution networks in a number of countries. It has been dosed in volumetric systems where liquid odorant is added proportionally to the volume of the flowing gas.

2. The use of sulphur-free odorants in evaporation-principle dosing systems is not advisable, judging from the course of the vapor pressure plots. There is a little possibility that the dosing tanks have such conditions that the odorant can be dosed selectively and the mutual participation of components of the odorant in natural gas will be different than in liquid odorant. Unsteady level of odorization is unacceptable and may lead to problems with obtaining proper intensity or required character of smell.

3. A relatively big number of odorization installations in Poland is based on the odorant evaporation mechanism. Another problem is related with gas supplies running to a given distribution system from a few input stations simultaneously. The plants supplying a given area happen to have both injection and contact installations, so when a new odorant is to be introduced the old-type systems have to be replaced. When planning modernization activities or new installations are to be made, the installations should be fully controlled and the odorant dosed proportionally to the flowing gas. It should be noted that in comparison with the cost of purchase the implementation of contact installations is not a sensible solution now.

4. The investigations prove the following advantages of the new odorant:

- stability in high pressure conditions,

- low adsorption on materials used in gas industry,

- low adsorption on dusts,

- low solubility in condensates.

5. Therefore, it can be successfully used for gas odorization in high pressure conditions. The use of sulphur-free odorant in Poland will mean a cheaper and more efficient odorization in central odorization systems in areas where this is justifiable. A change of the odorant shall allow for sending odorized gas at greater distances without the risk of losing the required smell level. The lack of negative impact of sulphur-free odorant on catalysts in the processing installations is another advantage.

6. The obligatory control of the odorization level twice a month is a problem now which should be solved prior to introducing a sulphur-free odorant to the pipelines. 
Preliminary actions were undertaken to check out the adaptability of certain chromatographs (presently used at laboratories) for determining acrylates. In the case of positive tests, there will be no need of buying expensive specialist equipment. On the side of disadvantages still remains the lack of possibility of measuring odorant concentration while performing simple exploitation activities with the use of miniature electrochemical detectors.

7. The use of sulphur-free odorant is a more attractive solution for environmentallyoriented customers. Combustion of gas without sulphur in it does not result in $\mathrm{SO}_{2}$ emissions. The effect of more clean energy in the primary energy carriers balance can be used for marketing purposes. Analogous to CNG-driven vehicles, the additional advantage will lie in lower carbon dioxide emissions and longer life of catalysts.

8. The economic data collected in Germany over a dozen of year show to the profitability of sulphur-free odorant. Slightly lower cost and slightly lower doses of this substance give savings of about $30-35 \%$ per volume of odorized natural gas. In Poland about 300 tonnes of THT are used each year. The yearly purchase of an odorant in Poland now may amount to about 3.5 to $4.0 \mathrm{mln}$ EUR. The potential savings on the odorant purchase itself may be equal to about $1 \mathrm{mln}$ EUR per year. The profits can be even bigger if we count the closed local odorization plants, reduced employment, lower number of unproved calls and zero taxes for sulphur dioxide emissions. The costs of implementation are connected with purchase of systems for determining low concentrations of acrylanes in gas and the replacement of the odorization system.

\section{REFERENCES}

[1] Bernhart, M.; Reimert, R.: Preliminary investigations on a sulphur-free odorant, Erdgas 10/1999.

[2] Cagnon, F.: New methodologies to help natural gas odorization, International Gas Union Research Conference 2011.

[3] Cornell, James C.: The Great International Disaster Book, Scribner 1996.

[4] Graf F.: Current developments in the odorization of natural gas in Germany, International Gas Union Research Conference 2008.

[5] Graff F., Kroger K., Reimert R.: sulphur-free odorization with Gasodor S-Free A Review of the accompanying research and development activities, Energy\&Fuels $2 / 2007$.

[6] Heine K., Schneider K.: Toxicological evaluation of carcinogenicity induced by ethyl acrylate, Symrise AG materials.

[7] Hess R.: Safety assessment of Gasodor S-Free, Symrise AG materials.

[8] Huszał, A.: Stabilność Gasodor S-Free w instalacjach i urzadzeniach nawaniajacych oraz jego oddziaływanie na materiaty stosowane $w$ gazownictwie, Nafta-Gaz, nr $12 / 2010$. 
[9] Kaesler H., Kämper J., Staudinger W.: S-Free odorant-experience with first major conversion projects, EON Ruhrgas materialss.

[10] Schunk C.; Bernhart M.; Reimert R.: A sulphur-free odorant-Greater environment friendliness while maintaining the level of safety, GWF-Gas/Erdgas, 10/1999.

[11] Tenkrat D., Hlincik T., Prokes O.: Natural Gas Odorization, InTech 2010, http://www. intechopen.com, 14.02.2014. 